\title{
Remediação com purpurina: bricolagens tecnoestéticas no drag-artivismo de Gloria Groove ${ }^{1}$ Remediation with glitter: techno-aesthetic bricolage in Gloria Groove's drag-artivism
}

\section{Rose de Melo Rocha}

Professora do Programa de Pós-Graduação em Comunicação e Práticas de Consumo da Escola Superior de Propaganda e Marketing, Brasil. Doutora em Ciências da Comunicação pela Universidade de São Paulo, Brasil. Pós-doutorado em Ciências Sociais/Antropologia, pela Pontifícia Universidade Católica de São Paulo, Brasil. Bolsista Produtividade em Pesquisa (CNPq). E-mail: rlmrocha@uol.com.br

\section{Resumo:}

Discute-se neste artigo a audiovisibilidade midiática da cantora drag paulistana Gloria Groove, nome artístico de Daniel Garcia, como exemplo de remediação tecnoestética em contextos pós-massivos. A prática artivista e as estratégias mercadológicas de Groove expressam uma habilidade bricoladora, na qual a presença no mainstream ou a larga repercussão de seu trabalho e da midiatização de suas narrativas existenciais não exclui as potencialidades críticas materializadas na junção entre corporalidade drag (travestida) e corporalidade gay (desmontada). É assim constituída uma politicidade do entre(tenimento).

\section{Palavras-chave:}

Gloria Groove; Drag-artivismo; Remediação; Tecnoestética; Pop pós-massivo.

\begin{abstract}
:
This article discusses the media audio-visibility of the São Paulo's drag singer Gloria Groove, the artistic name of Daniel Garcia, as an example of techno-aesthetic remediation in post-mass contexts. Groove's artivist practice and marketing strategies express a bricolational skill in which the mainstream presence or the large-scale repercussion of his work and existential narratives does not exclude the critical potentialities embodied in the junction between drag (transvestite) corporality and gay corporality (dismantled). It thus constituted a politics of entertainment.
\end{abstract}

\section{Keywords:}

Gloria Groove; Drag-artivism; Remediation; Techno-aesthetic; Post-mass Pop.

\section{Remediação e missão drag}

\footnotetext{
${ }^{1}$ Pesquisa realizada em parceria com Thiago Henrique Ribeiro dos Santos. Jornalista, especialista em Jornalismo Cultural pela PUCSP, mestrando do PPGCOM-ESPM. E-mail: thiago.rizan@gmail.com
}

INTERIN, v. 23, n. 1, jan./jun. 2018. ISSN: 1980-5276. 
Que negócio é esse daí?

É mulher?

Que bicho que é?

Prazer, eu sou arte, meu querido

(Dona, Gloria Groove)

Trabalharemos neste artigo com o conceito de remediação a partir especificamente de leituras que enfatizam as dimensões e implicações culturais atinentes a tal processo, prevendo, ainda, as mudanças causadas pelos saltos que sucessivamente se operaram nas ambiências comunicacionais e tecnológicas, do analógico ao digital, do massivo ao pós-massivo, da remediação à transmediação. Assim, dialogamos com a proposta de reconfiguração sintetizada por Lemos (2005) na máxima "tudo muda, mas nem tanto":

[a] idéia de reconfiguração vai [...] além da remediação de um meio sobre o outro (por exemplo o cinema nos jogos eletrônicos e vice-versa). Por reconfiguração compreendemos a idéia de remediação mas também a de modificação das estruturas sociais, das instituições e das práticas comunicacionais. (LEMOS, 2005, p. 8).

Partindo do conceito clássico de remediation (BOLTER; GRUSIN, 2002), Lemos é um dos primeiros autores brasileiros a perceber a plasticidade e a embocadura cultural que caracterizam as visadas tecno-informacionais em suas múltiplas dobraduras, e, ao fazê-lo, não adere seja a críticas totalmente céticas, nem a voluntarismos cabalmente engessados. É, afinal, a cultura que potencialmente se remixa ainda que nem todas as pessoas tornem-se potenciais remixadoras. Mas é indubitável que a digitalização tecnológica e a descompressão dos pólos emissores (antevistos por Edgar Morin em seus escritos dos anos sessenta como destino emblemático de uma crise positiva e irreversível na cultura de massas) abriram brechas e ranhuras que foram progressivamente ocupadas por sujeitos e subjetividades bricoladoras.

Morin percebera com um misto de ironia e otimismo como as dissidências estelares cristalizadas nas figuras de James Dean e de toda uma geração de mitologias cinematográficas de outsiders foram encampadas pelas telas hollywoodianas e ofertadas em doses mais ou menos palatáveis a uma legião de consumidores ávidos por suspense e acesso ao interdito. Um consumo sacrificial e um tanto perverso canibalizava à distância a simbiose entre ficcional e factual que

INTERIN, v. 23, n. 1, jan./jun. 2018. ISSN: 1980-5276.

Rose de Melo Rocha; Thiago Henrique Ribeiro dos Santos. Remediação com purpurina: bricolagens tecnoestéticas no dragartivismo de Gloria Groove. p. 205-220. 
levaria muitos destes bad-boys e garotas boas-más (PROKOP, 1986) a destinos trágicos em vida.

No seio de uma ciber-cultura-remix (LEMOS, 2005) e em contextos de transmediação as dobraduras podem, por vezes, conduzir a outros devires comunicacionais, culturais, existenciais, políticos. Levando para o "aqui-agora" e o mundo comezinho o campo da celebrização e a auto-gestão de visibilidade, a virada digital e a comunicação em rede não apenas empobreceram a experiência - embora muitas vezes participem ativamente deste processo. Toda uma geração de jovens periféricos, no sentido lato da palavra, toma para si as máquinas de narrar pósmassivas e, mais de uma vez, têm perfurado as paredes de cristal dos condomínios de classe, de acesso, de etnia, de gênero.

Não foram apenas empreendedores convencionais, reproduzindo e zelando pelas ordens conservadoras do capital, os que surgiram neste contexto de apropriação cultural juvenil, que ganham força exponencial a partir dos anos 2010. A cultura pop foi também re-remixada, re-remediada, dando espaço para o protagonismo de atoresprodutores-performers que tradicionalmente não ocupariam o espaço nobre de "casas de família", "casas de shows" ou de salas de estar midiáticas, a não ser que em tom anedótico, estigmatizador e/ou exotizante. E, isto, por suas origens desclassificadas ou condições desviantes.

Agora, ao contrário, “olha só como o jogo virou Do nada cê liga a TV Nóis tá na Globo E abre espaço pras donas sem torcer o nariz Que elas já chegam no estilo Imperatriz", testemunha Gloria Groove, na canção Imperatriz. É a hora e a vez das insurgências-remix, do glitter-subcultural, do pop-pós-periférico. Seriam mitológicas nossas bandivas da queer-music? Retornaremos a este tema em outra de nossas escritas, e nos será fundamental dialogar para tal empreitada com as proposições - e as desconfianças - de Paludo (2017), que diferencia "mitos musicais" de celebridades produzidas a granel, sem densidade, em grau zero de inconformismo e virtuosismo.

É-nos cara ao argumento que agora desenvolvemos a proposição feita por Guimarães (2007) ao circunscrever criticamente o conceito de tecnoestética no debate das mutações da experiência e do devir artístico em contextos digitais. Ainda que a pesquisadora tenha por ênfase a análise de produtos audiovisuais inseridos em 
meios e formatos televisuais e videoartísticos, que independem, para sua análise de então, dos contextos transmediados de produção e recepção, acreditamos ser possível estender a aplicação do conceito à cena comunicacional pós-massiva tal como hoje se apresenta; e sendo esta na qual se inserem os produtores e os produtos audiovisuais que estudamos.

A contribuição de Cádima (2015) às reflexões sobre convergência midiática corrobora esta hipótese. Segundo sua interpretação,

[...] o novo paradigma digital está a determinar a integração de conteúdos emergentes da intersecção das digital humanities e dos new media, designadamente nos âmbitos culturais, científicos e criativos, em especial nas áreas da comunicação, do cinema, da música e das artes, mas também nas ciências em geral. [...] Com a migração do sistema de mídia clássico para as novas mídias, reformulou-se o próprio paradigma comunicacional e um novo dispositivo pós-televisivo emergiu. Interatividade, ubiquidade, imersão, hibridez, matricialidade, remediação são conceitos que procuram identificar essa inflexão do novo dispositivo da comunicação. (CÁDIMA, 2015, p. 194).

Cádima sugere ser relevante a visão de Jesus Martín-Barbero, quando apresenta a dualidade palimpsesto/hipertexto, mas isto o levaria a considerar que

[...] esse efeito de translação não é apenas memória e sentido, mas também construção social e simbólica, sobretudo quando as componentes tecnológicas e os dispositivos técnicos interferem no próprio processo criativo, evoluindo para uma remediação ou para uma conversão/translação, o que significa que o novo processo, sobretudo em contextos digitais, é, em si mesmo, um híbrido no qual essas duas componentes se completam e se reforçam.... (CÁDIMA, 2015, p. 195).

Tomar a remediação a partir da dimensão tecnoestética e a bricolagem a partir do devir drag são perspectivas fundamentais que se unem na problematização do modo como o artivismo tecno-pop de Gloria Groove caracteriza seu modo específico de presença nas práticas de designação queer-musicais. A "fusão do experimentalismo com o entretenimento" que Guimarães associa a "uma redescoberta do prazer estético, como algo não necessariamente vinculado ao enigmático, obscuro ou elitizante" (GUIMARÃES, 2007, p.7) é notada em parte das poéticas audiovisuais trans e dragartivistas.

Também ali, o “entre-imagens”, que Guimarães recupera em Raymond Bellour, remete, em nosso ponto de vista, a um entre-campo perceptual, capturando o

INTERIN, v. 23, n. 1, jan./jun. 2018. ISSN: 1980-5276. 
vidente para a instabilidade constitutiva do estar/estado drag em situação de audiovisualidade, e, metafórica ou imaginariamente, levando à partilha da reflexividade protagonizada pelos músicos-performers. Assim, seguindo o raciocínio de Guimarães, temos que novas formas de (áudio)visibilidade em que o valor que se contrata é o da "recriação", poderiam efetivamente ser associados ao que temos chamado políticas de audiovisibilidade artivistas, propostas táticas táteis que muito bem tipificam as expressividades criativas remediadas e remixadas das divas tecnodrags.

Estes autores nos ajudam a traçar uma cartografia analítica capaz de dar conta da hipótese de pesquisa que objetivamos apresentar neste artigo. Também vão compor o cabedal de chaves de leitura que temos utilizado na análise de fenômenos contemporâneos de pop-artivismo, bem como de seus contextos de circulação e recepção. Temos nos dedicado especificamente ao mapeamento e análise das produções midiáticas e dos circuitos de audiovisibilidade pós-massivos articulados e ativados pelo aparecimento e consumo de cantores (nascidos, criados ou vivendo no estado de São Paulo) vinculados ao que está sendo nomeado, desde uma fala nativa (e não apenas pelos meios de comunicação hegemônicos) como música-queer e que temos, juntamente com alguns membros do JUVENÁLIA ${ }^{2}$, buscado conceituar como trans-artivismo audiovisual, que enseja políticas de audiovisibilidade do entre(tenimento).

Os circuitos de energização (LIENSENBERG, 2015) ativados por nossos sujeitos de pesquisa configuram um momento de recepção dilatado e de bordas expandidas, uma vez que foram engendrados a partir de um solo comunicacional convergente e transmidiático. Ou seja, a análise ora proposta da cantora drag Gloria Groove considera que esta persona midiática constitui com sua presença urbanodigital uma cena ou acontecimento que ultrapassa os limites estritos de videoclipes produzidos e shows realizados, supondo não só uma audiência complexa e policêntrica, mas valendo-se da base dilatada que conecta canais próprios e geridos por fãs no YouTube, em blogs, páginas no Facebook, Twitter e Instagram, presença em programas da televisão comercial aberta e fechada, palestras, participação em debates e festas, dentre outros.

\footnotetext{
${ }^{2}$ https://www.facebook.com/groups/juvenalia/

INTERIN, v. 23, n. 1, jan./jun. 2018. ISSN: 1980-5276.
} 


\section{Convoca todas bandidas!}

"Chama o bonde todo que quem chegou é a dona do jogo: Gloria Groove é a mina que veio da Zona Leste de São Paulo para mostrar que cultura drag é missão dando um salve a todas as montadas dessa nação!"3 Sua glória começou em 2014, quando, aos 19 anos, teve suas primeiras experiências com montagem ${ }^{4}$ no teatro musical e descobriu o reality show RuPaul's Drag Race (GROOVE, 2017a). "Filha do YouTube" (GROOVE, 2015a), encontrou nos ambientes digitais o território fértil para compartilhar sua produção de conteúdo midiático. Seu canal homônimo no YouTube possui 96 mil inscritos, 11 milhões de visualizações e 19 vídeos, sendo 10 com áudios de músicas autorais, 3 videoclipes, 2 covers, 2 bastidores de turnê, 1 teaser de videoclipe e 1 apresentação de show em casa noturna ${ }^{6}$.

Daniel Garcia Felicione Napoleão, artisticamente conhecido como Gloria Groove, possui em sua experiência como cantor, performer e dublador o trânsito por diferentes espaços do mainstream. Participou, ainda criança, de shows de calouros na televisão brasileira, e chegou a compor um conhecido grupo infanto-juvenil brasileiro, o Balão Mágico. Adulto, transita pelo underground, no "fervo" LGBT, mas, mais especificamente, começa a se montar no teatro musical. Exímio pesquisador de linguagens musicais, coreográficas e videográficas, Daniel reporta à imagem do bricolador, daquele que constrói sua marca autoral não só na composição de letras e cenarizações impecáveis em videoclipes, mas na articulação criativa de

\footnotetext{
${ }^{3}$ Referências à letra da música Dona, de Gloria Groove.

${ }^{4}$ Montagem (SANTOS, 2012) ou montaria (VENCATO, 2002) é o processo no qual o sujeito manipula sua corporalidade através de tecnologias provisórias, como maquiagem, figurino, perucas, próteses etc., para construir um corpo outro. Ressalta-se, todavia, que a montagem não é exclusividade drag queen: "De acordo com situações específicas em contextos especiais, algumas pessoas recorrem a processos parecidos com a montagem das drags para investir em uma posição, como também para pertencer a determinado grupo" (SANTOS, 2012, p. 96). É o caso de juízes de Direito que se montam ao vestir a toga e adquirir uma seriedade que não necessariamente faz parte do seu cotidiano ou sacerdotes em cerimônias religiosas.

${ }^{5}$ RuPaul's Drag Race é um reality show de competição no qual drag queens disputam o título de America's Next Drag Superstar e a posição de continuar o legado da criadora, produtora e apresentadora do programa, RuPaul. Estreou em 2009 e possui nove temporadas. Até a oitava temporada foi transmitido, nos Estados Unidos, pelo canal LogoTV e, a partir da nona, pela VH1. No Brasil, há sete temporadas disponíveis na plataforma de streaming Netflix.

${ }^{6}$ Dados de setembro de 2017.
} 
uma miríade de referenciais advindas dos sistemas especialistas massivos e das ferramentas tecnológicas.

Ainda que existam registros de cantoras na cultura drag queen ocidental como Danny La Rue, na Inglaterra dos anos 60/70 (BAKER, 1994), e RuPaul, nos Estados Unidos, desde 1990, apenas para citar dois nomes representativos -, Gloria Groove, tal como Pabllo Vittar ${ }^{7}$, se destaca na cena drag brasileira por ser uma cantora profissional e ter músicas autorais, em uma cultura que tem como uma de suas características os shows de dublagens.

De uma família de artistas, com avó profissional de circo, avô pianista, mãe e tias cantoras, a primeira expressão musical de Daniel Garcia acontece, aos quatro anos, cantarolando Hero, de Maria Carey (GROOVE, 2017d). Desde então, ele conta em entrevistas ter se familiarizado com estúdios de gravação, acompanhando a mãe em sua carreira, e trabalhado com dublagem desde os nove anos de idade. Evangélico até os 14, quando se assumiu gay e se distanciou da Igreja, ainda traz no nome drag esse período. Glória refere-se à interjeição de prosperidade utilizada em contextos evangélicos, e, como ela explica:

Gosto também porque não é só um nome, é uma palavra que significa alguma coisa. E o Groove veio depois, com a necessidade de achar um G que completasse ${ }^{8}$. Eu trabalhava com uma banda Supersom, nessa época. Eu percebia que os músicos falavam bota um pouco mais de groove nesse som, pra ficar com um pouco mais de pegada. Ninguém precisava falar o que era groove, era o espírito da música que tava ali rondando no meio de todo mundo. Falou groove, entendeu. (GROOVE, 2017d).

A travestilidade drag queen por vezes é confundida com outras metamorfoses de gênero (SANTOS, 2012), pois, como a própria Groove (2016c) afirma, "para parte da população, como somos muito marginalizados, muitas vezes somos colocados no mesmo pacote que transgêneros. As pessoas não separam trans, drag, travestis e não entendem a função de cada uma delas". Sendo este um artigo que intenta discutir a atuação de uma drag em particular, se faz necessária uma breve explanação sobre quem é esse sujeito para, então, avançarmos na discussão.

\footnotetext{
7 Para uma discussão sobre a atuação da drag queen brasileira PablloVittar, consultar ROCHA e POSTINGUEL (2017).

${ }^{8}$ Groove (2017) explica que as iniciais de sua mãe são GGG e, quando criança, a acompanhou em um show no qual ela fez backing vocal para a cantora estadunidense Gloria Gaynor: "Fui criando fascínio com GG, associando com cantora, mulher. O GG [de Glória Groove] veio com essa obsessão pela letra".
}

INTERIN, v. 23, n. 1, jan./jun. 2018. ISSN: 1980-5276. 
“Drag queens não são, quando muito estão. Mas nunca se sabe realmente”. A afirmação da antropóloga Anna Paula Vencato (2002, p. 116, grifos da autora) é fundamental para começarmos a nos aproximar de uma compreensão do que é ser drag queen e de como esta expressão se diferencia de outras travestilidades, como as de travestis, crossdressers, transgêneros, crossplayers, etc. Vencato (2002) auxilia nessa tarefa ao propor três características balizadoras para se pensar a drag queen: temporalidade, corporalidade e teatralidade.

Temporalidade porque a drag acontece em três tempos: desmontada, se montando e montada, ou seja, há começo, meio e fim. Etnografias com drag queens no Brasil e nos Estados Unidos reforçam que não é desejo unívoco de tais sujeitos estar mulher em tempo integral, sendo esta, inclusive, uma característica que algumas delas utilizam para se diferenciar de travestis (VENCATO, 2002; SANTOS, 2012; NEWTON, 1972). Nesse processo, o uso de pronomes é cambiante e exprime as negociações entre intérprete e personagem, revelando em qual momento da temporalidade drag o sujeito está. "Eu não vou ligar se você me chamar de ele, mas eu vou gostar mais se você me chamar de ela, porque levou um tempo pra ficar ela", brinca Groove (2017c). Não obstante, quando retorna ao seu corpo anterior à transformação, a drag queen deseja ser referenciada no masculino (SANTOS, 2012): "Sou homem, cisgênero, gay. Esse é meu trabalho, drag é uma expressão artística. Eu não sou uma mulher 24 horas por dia", conclui Groove (2017a).

A segunda característica, corporalidade drag (VENCATO, 2002), diz respeito ao corpo como território de transformação. Com o auxílio de tecnologias provisórias, como maquiagem, perucas, próteses e figurinos, e em diferentes intensidades, o corpo considerado socialmente masculino do intérprete é redesenhado temporariamente. Joseylson Fagner dos Santos (2012) compreende esse processo como uma transitoriedade dos corpos, pois a metamorfose conseguida através de truques de ilusão não compromete a anatomia do intérprete.

Por fim, a teatralidade diz respeito à representação fictícia do corpo drag. Não por acaso, foi no teatro musical que Gloria Groove fez suas primeiras experimentações de montagem. Ela observa:

Pra mim, se montar vai além do negócio de se vestir de mulher, pra mim é se preparar para estar no palco de um jeito mais legal. Com a máscara,

INTERIN, v. 23, n. 1, jan./jun. 2018. ISSN: 1980-5276.

Rose de Melo Rocha; Thiago Henrique Ribeiro dos Santos. Remediação com purpurina: bricolagens tecnoestéticas no dragartivismo de Gloria Groove. p. 205-220. 
isso a gente aprende muito no teatro o tempo todo, com a máscara você tem outra segurança, você pode muito mais. (GROOVE, 2015a).

Há, ainda, a compreensão de tal ato como performance no sentido de evento artístico de Richard Bauman (1986 apud VENCATO, 2002). Para ele, o performer logo, a drag como tal - é capaz de causar conforto/desconforto, manter/subverter a ordem e ter ou não a atenção da audiência. É importante destacar que em seus videoclipes Groove convive com Daniel, recurso narrativo de provocação e afirmação assumido pelo próprio. Vencato (2002, p. 114) considera que a relação entre drag e sujeitos presentes nos territórios onde ela circula é justamente de constante tensão: “A experiência drag se constrói muito em relação ao corpo que se monta, que é montado, e nas negociações que esse corpo [...] estabelece com outros sujeitos".

Quanto aos territórios de atuação da drag queen, onde ocorrem tais tensões, eles são diversos e incluem casas noturnas, Paradas do Orgulho LGBT, bailes de Carnaval, concursos de beleza, eventos públicos e privados, entre outros espaços. Mas, desde os anos 2000, contudo, eles não estão mais circunscritos a espaços físicos. Para além deles, no fluxo das transformações sociais promovidas pelas tecnologias digitais, as drags estão se apropriando do ambiente digital e se posicionando de uma maneira inédita: como produtoras de conteúdo, formatos e formas autorais e contribuindo, assim, para uma explosão midiática internacional da cultura drag (SANTOS, 2017).

Gloria Groove transita entre espaços das mídias alternativa e tradicional. No YouTube, há diversas entrevistas para o que parecem ser programas de TV ou programas web locais das cidades onde faz shows, mas também já teve seu clipe Império exibido na MTV Brasil, estampou a capa da revista Trip e participou do programa Amor \& Sexo, da Rede Globo. Nesse trânsito ocupacional, entretanto, é no ambiente digital que predomina sua produção de formatos e conteúdo.

Groove faz parte do que Clay Shirky $(2011$; 2012) chama de cultura da participação, um sistema no qual não há mais a distinção entre consumidores e produtores de conteúdo que caracterizou os meios de comunicação de massa do século XX. Se cinema, rádio, televisão, jornais e revistas detinham o privilégio de produzir e compartilhar conteúdo, no século passado, restando à audiência apenas consumi-lo, a ciber-cultura-remix (LEMOS, 2005) subverteu essa lógica, 
possibilitando aos seus usuários consumir, mas, igualmente, produzir e compartilhar. Com o baixo custo envolvido no uso das tecnologias digitais, sujeitos anônimos libertam-se da necessidade da infraestrutura tecnológica e humana financeiramente dispendiosa da mídia tradicional.

Estamos vivendo no meio do maior aumento da capacidade expressiva na
história da raça humana. Mais pessoas podem comunicar mais coisas para
mais pessoas do que jamais foi possível no passado, e o tamanho e a
velocidade desse aumento, que foi de menos de 1 milhão para mais de 1
bilhão de participantes no decorrer de uma geração, fazem da mudança
algo sem precedentes. (SHIRKY, 2012, p. 57).

Não por acaso, é no ambiente digital que, em fevereiro de 2017, Groove lançou seu primeiro álbum, $O$ Proceder. Ele está disponível na íntegra, gratuitamente, em seu canal oficial no YouTube, na plataforma de streaming Spotify e para compra na loja virtual iTunes. O trabalho conta com oito músicas originais, sendo que quatro delas (Dona, Império, Gay (Interlúdio) e O Proceder) problematizam vicissitudes drag queen e/ou LGBT e quatro (Muleke Brasileiro, Problema, Gloriosa e Madrugada) possuem letras sobre ostentação e relacionamentos amorosos (SANTOS, 2017).

Quanto à estética musical, é possível identificar que a drag apropria-se de elementos do soul, R'n'B, rap e hip hop para criar uma sonoridade pop. Sobre tal mixagem com a cultura $\mathrm{drag}$, Groove reconhece uma originalidade conflituosa, pois "o hip hop e o rap, um meio dominado por homens, extremamente machista, misógino, vai contra tudo que drag faz" (GROOVE, 2017c). Mas, uma vez que tais estilos foram preponderantes na modulação de seu gosto musical, seria inevitável sua convergência: "Se o hip hop e o rap é [sic] uma parte de mim muito grande que eu considero, e drag também, não tem porque não conseguir juntar" (GROOVE, 2017c).

A própria estética de Gloria Groove é um mosaico de referências tal qual sua sonoridade. Sempre muito polished ${ }^{9}$ em suas aparições midiáticas, ela, predominantemente, apresenta uma cabeleira com cachos armados ou longas tranças,

\footnotetext{
${ }^{9} \mathrm{O}$ termo é comumente utilizado no universo drag queen de língua anglo-saxônica para se referir a uma estética sofisticada e bem executada, diferentemente das estéticas genderfuck e caricata. No RuPaul's Drag Race Dictionary, a palavra é definida como um adjetivo "usado para se referir a uma drag queen cujo look é considerado impecável, bem executado e perfeito" (SANTOS, 2017, tradução nossa).
}

INTERIN, v. 23, n. 1, jan./jun. 2018. ISSN: 1980-5276. 
enquanto realça suas curvas em cintilantes maiôs colados ao corpo. Seus figurinos aludem ao glamour das divas do pop estadunidense em negociação com supostas características nacionais, como o corpo curvilíneo de algumas mulheres brasileiras e o cabelo afro ou trançado da comunidade negra.

Uma Beyoncé brasileira ou uma Elza Soares estadunidense? No contexto pósmoderno de remediação do conceito de autoria, com a fragmentação e a força de uma cultura criativa recombinante em que se corta, se recorta e se fusiona, palimpsesta e hipertextualiza os trabalhos de outros artistas para criar a sua própria arte, talvez, o mais indicado não seja ou, mas $e$. É Beyoncé brasileira $e$ Elza Soares estadunidense, $e$ Nicki Minaj, e Ludmilla, e Anitta, $e$ Mariah Carey, $e$ Kanye West, $e$ tantos outros (es)citados em suas falas, durante entrevistas diversas.

O caleidoscópio artístico cortado, recortado e montado por Groove se localiza na ciber-cultura-remix sobre a qual André Lemos (2005) escreve. Regida pelo princípio da re-mixagem, um "conjunto de práticas sociais e comunicacionais de combinações, colagens, cut-up de informação a partir das tecnologias digitais" (LEMOS, 2005, p. 1), tal dinâmica tem afetado os processos comunicacionais e sociais contemporâneos, incluindo a criação artística.

Uma vez que a cibercultura não é um universo paralelo ao que já foi considerado o mundo real, as tecnologias digitais "tornam-se cada vez mais os instrumentos coordenadores de eventos no mundo físico" (SHIRKY, 2011, p. 37). Nota-se, então, uma articulação entre a cultura da participação de Shirky (2011; 2012) e a ciber-cultura-remix de Lemos (2005), sendo elas profundamente tocadas pela lógica de produção, compartilhamento e consumo com e das tecnologias digitais.

Afetada por essas transformações, Groove (2016a) aprendeu a se maquiar assistindo a tutoriais na internet e admite o ambiente digital como pilar fundamental para sua carreira:

Eu com certeza não teria o mesmo impacto e nem a mesma visibilidade se não fosse o poder da internet e da comunicação da era em que a gente vive. Ela ajuda a gente a se comunicar, se divulgar, se fazer entender e ainda nos entretém na maioria das vezes. As coisas aconteceram muito rápido pra mim, e a internet exerceu um papel muito grande pra que isso acontecesse. (GROOVE, 2016a). 
É de lá, da rede, que vem não apenas o acesso às cantoras com as quais se identifica, mas também as referências para o conteúdo de algumas de suas letras. Em O Proceder, Groove invoca um processo de copyleft (LEMOS, 2005) ao apropriar-se de uma miríade de memes ${ }^{10}$ da cultura digital. Em momentos diferentes, ela canta:

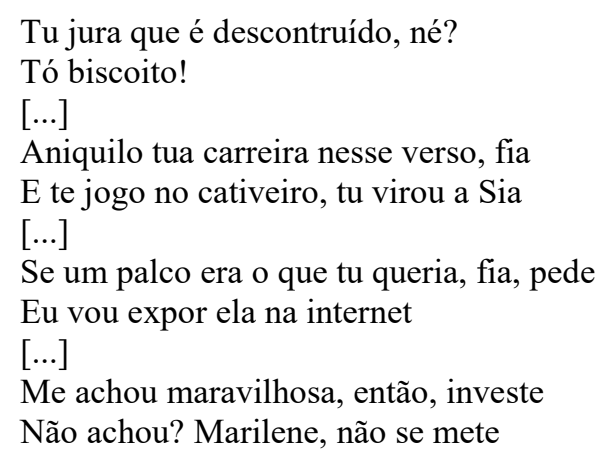

"Tó biscoito", na cultura dos memes, é utilizado para sugerir que a outra pessoa está querendo chamar atenção; "E te jogo no cativeiro, tu virou a Sia" referese a uma teoria da conspiração de que Beyoncé manteria a cantora Sia presa em um cativeiro, compondo músicas para ela ${ }^{11}$; "Eu vou expor ela na internet" é um meme da série de animação Disk Duny, disponível no YouTube, e que parodia uma briga pública entre a socialite Kim Kardashian e a cantora Taylor Swift ${ }^{12}$; e, por fim, "Marilene, não se mete" conecta-se a um vídeo que se popularizou na internet brasileira, em 2016, de uma garota brasileira contando sobre o flerte com um cantor, quando é desmascarada pela mãe, ao que responde: "Marilene, não se mete"13.

O que Groove faz é pinçar os memes e intervir em seus formatos, recortandoos de seus contextos originais, transformando-os em música e localizando-os em seu discurso artístico. Cada uma dessas estrofes ilustra o princípio da remixagem, que se refere à "apropriação, desvios e criação livre [...] a partir de outros formatos,

\footnotetext{
${ }^{10}$ Segundo a definição do Museu dos Memes, da Universidade Federal Fluminense, "meme é um fenômeno típico da internet, e pode se apresentar como uma imagem ou analogia, uma frase de efeito, um comportamento difundido, um desafio". Disponível em: <http://www.museudememes.com.br/oque-sao-memes/>. Acesso em: 23 set. 2017.

11 Disponível em: <https://www.buzzfeed.com/ryanhatesthis/por-dentro-dessa-teoria-conspiratoriatotalmente-p?utm_term=.laBWB2VZ7\#.baJz8abew>. Acesso em 23 set. 2017.

${ }^{12}$ Disponível em: $<$ https://www.youtube.com/watch?v=f5e6xCUUOrQ>. Acesso em 23 set. 2017.

${ }^{13}$ Disponível em: < https://oglobo.globo.com/cultura/marilene-nao-se-mete-21499150>. Acesso em 23 set. 2017.
}

INTERIN, v. 23, n. 1, jan./jun. 2018. ISSN: 1980-5276. 
modalidades ou tecnologias, potencializados pelas características das ferramentas digitais e pela dinâmica da sociedade contemporânea" (LEMOS, 2005, p. 2).

A música Gay (Interlúdio), por exemplo, é um enfrentamento musicado no qual Groove reforça em cada verso a (homo)sexualidade do interlocutor, se apropriando do termo pejorativo, em um processo de ressignificação semelhante ao dos estudos queer. Ela diz: "Uma vez que você está em paz com o fato que você é uma bichona, sim, que você é preta, sim, que você é tudo isso, sim, não tem como ninguém mais te atingir por conta desses fatores" (GROOVE, 2017c). Sua construção poética aconteceu depois que a drag ouviu I Love Kanye, do último álbum de Kanye West. Na música, o rapper estadunidense repete o próprio nome em cada frase. "Eu pensei o quanto isso ficaria legal refletido numa coisa que a gente pudesse se ver”, explica Groove (2017a). Assim, ela chegou à seguinte formulação, emblemática, em termos rítmicos, do groove que compõe seu nome:

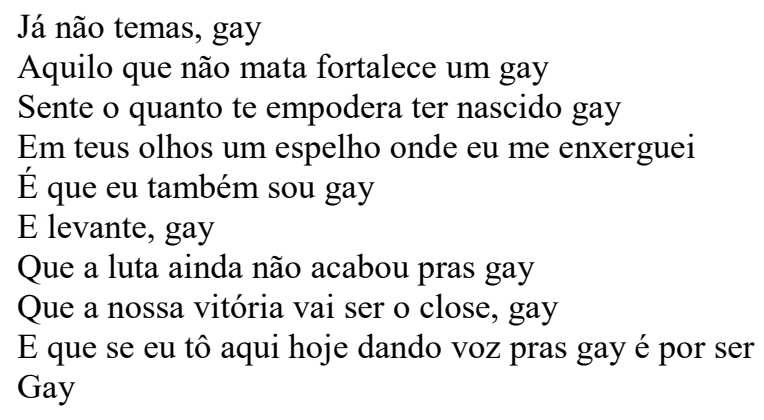

E não é só "dando voz pras gay" que Groove atua. Mesmo sua composição artística tendo surgido como uma estratégia de inserção no mercado fonográfico (GROOVE, 2017a; GROOVE, 2016b), ela, também, opera políticas de visibilidade e visualidade de negros e drags.

De uma forma ou outra eu estou dando voz pra essas três minorias que eu
represento: o gay, que a gente sabe como isso é tratado e como a gente
ainda é visto dentro do nosso país, principalmente; a drag queen, que é
muito marginalizada; e o negro, que é muito inferiorizado ainda e
hostilizado. Então, pra mim, é uma honra, por exemplo, subir no palco e
mostrar pra qualquer gay, drag ou negro que é possível, sim, você fazer
disso a melhor coisa que há em você. É possível que você leve isso a
outro nível e pegue justamente aquilo que as pessoas dizem pra você que
não é legal e faça disso a melhor coisa da sua vida. (GROOVE, 2016b).

INTERIN, v. 23, n. 1, jan./jun. 2018. ISSN: 1980-5276.

Rose de Melo Rocha; Thiago Henrique Ribeiro dos Santos. Remediação com purpurina: bricolagens tecnoestéticas no dragartivismo de Gloria Groove. p. 205-220. 
Gloria Groove usa das tecnologias digitais para se tornar visível na esfera pública conectada, pois

\footnotetext{
[o]s novos ambientes digitais representariam (..) ao menos potencialmente (...) uma multiplicação de esferas públicas, ampliando quantitativamente e qualitativamente os espaços disponíveis para o debate racional dialógico. (MAGRANI, 2014, p. 58-59).
}

Esta trilha de análise prevê o fluxo como regra e o trânsito como modo de performar arte e pertencimento, música e subjetivação. Neste sentido, entendemos que Gloria Groove é representante de uma ação comunicacional intencional e propositiva de remediação política-artivista. Drag glamorosa e homem potente, redesigna modos e territórios de afirmação subjetiva, nos quais a ação artística configura um espaço de tensão e negociação, tanto de legitimidade social, quanto de legibilidade expressiva. No modo dilatado que une narrativa audiovisual midiatizada e audiências multifacetadas e ubíquas, Groove cola no tecido social a pele da cultura drag. Este entre-lugar midiático tece brechas sociais efetivas. Como sugerem Amaral e Soares (2017) é nesta direção que a ritualística artística, disparada em cena, seguirá se espraiando por lugares outros de ritualização. E, neles, talvez possamos, vez ou outra, performar alteridades. Em memória e em presença. Gloriosamente rasurados.

\section{REFERÊNCIAS}

AMARAL, Adriana; SOARES, Thiago. O Queen, a Queen: Controvérsias sobre gêneros e performances. Revista Famecos. Porto Alegre, v. 24, n. 1, janeiro, fevereiro, março e abril de 2017.

BAKER, Roger. Drag: A History of Female Impersonation in the Performing Arts. Nova Iorque: New York University Press, 1994.

BERTHOLD, Margot. História mundial do teatro. São Paulo: Perspectiva, 2001.

BOLTER, J.D, GRUSIN, Richard. Remediation. Understanding New Media. MIT Press, 2002.

CÁDIMA, Francisco Rui. Novas convergências digitais: mídia, humanidades e artes. Revista Novos Olhares - Vol.4 N.1. 2015. 
GROOVE, Gloria. Bibs Entrevista - Glória Groove. Biblioteca, 11 ago. 2017a. Disponível em: $<$ https://www.youtube.com/watch?v=Nf09IL91OFk $>$. Acesso em 22 set. 2017. Entrevista.

.Entrevista com Gloria Groove. TV Farofa, 19 ago. 2017b. Disponível em: $<$ https://www.youtube.com/watch?v=K81ZLJg_o4o $>$. Acesso em: 10 set. 2017. Entrevista.

. Gay nerd | O ritmo e a attitude de Glória Groove. Omelete, São Paulo, SP, 05 mar. 2016a. Disponível em: $<$ https://omelete.uol.com.br/colunistas/artigo/gaynerd-o-ritmo-e-atitude-de-gloria-groove/>. Acesso em: 22 set. 2017. Entrevista.

Gloria Groove | Entrevista TNAV. Tudo Nada a Ver, 17 maio 2016b. Disponível em: $<$ https://www.youtube.com/watch?v=MN8wjv6Hdgc $>$. Acesso em: 17 set. 2017. Entrevista.

Gloria Groove diz que a cultura drag no Brasil ainda precisa de valorização. Uai, 8 set. 2016c. Disponível em: $<$ http://www.uai.com.br/app/noticia/emais/2016/09/08/noticia-e-mais, 183941/gloria-groove-diz-que-a-cultura-drag-nobrasil-ainda-precisa-de-valori.shtml $>$. Acesso em: 17 set. 2017. Entrevista

Gloria Groove, a dona da porra toda. Trip TV, 16 jan.2017c.

Entrevista.Disponível em: $<$ https://www.youtube.com/watch? $\mathrm{v}=645 \mathrm{zC} 5 \mathrm{voon0}>$. Acesso em 16 set. 2017. Entrevista.

. PGM 54 - Na Mira com Gloria Groove. TV Clicaki, 20 maio 2017d. Disponível em: $<\underline{\text { https: } / / w w w . y o u t u b e . c o m / w a t c h ? v=T r c p x C T v-i A ~}>$. Acesso em: 22 set. 2017. Entrevista.

. Please don't stop the mousse. Tempero Drag, 13 jul. 2015a. Disponível em: $<$ https://www.youtube.com/watch?v=GxHg16rzoII $>$. Acesso em: 14 set. 2017. Entrevista.

Projeto Ruídos: Entrevista com Gloria Groove. Caleidoscópio. CreativeLab, 6 abr. 2015b. Disponível em: $<$ https://www.youtube.com/watch?v=SG9G-_CqUr0 $>$. Acesso em: 17 set. 2017. Entrevista.

GUIMARÃES, Denise Azevedo Duarte. Comunicação tecnoestética nas mídias audiovisuais. Porto Alegre: Sulina, 2007.

LEMOS, André. Ciber-cultura-remix. São Paulo, Itaú Cultural, agosto de 2005. Disponível em: $<$ http://sciarts.org.br/curso/textos/andrelemos_remix.pdf $>$. Acesso em 17 set. 2017.

LIESENBERG, Susan. A energização na internet: delineamentos de um conceito em construção. In: XXXVIII Congresso Brasileiro de Ciências da Comunicação. 2015. Anais eletrônicos. Disponível em: 
$<$ http://portalintercom.org.br/anais/nacional2015/lista area DT6-CU.htm $>$. Acesso em 27 set. 2017.

MAGRANI, Eduardo. Democracia conectada: a internet como ferramenta de engajamento político-democrático. Curitiba: Juruá, 2014. Disponível em: http://bibliotecadigital.fgv.br/dspace/bitstream/handle/10438/14106/Democracia\%20 conectada.pdf. Acesso em: 02 set. 2017.

NEWTON, Esther. Mother Camp: Female Impersonators in America. Chicago e Londres: The University of Chicago Press., 1972.

PALUDO, Ticiano. Mitologia musical. Estrelas, ídolos e celebridades vivos em eternidades possíveis. Curitiba: Appris, 2017.

PROKOP, Dieter. Coleção Grandes Cientistas Sociais. São Paulo: Ática, 1986.

SANTOS, Thiago Henrique Ribeiro dos. As donas da porra toda: uma leitura política da produção de conteúdo autoral nas mídias alternativas das drag queens Lorelay Fox, Gloria Groove, PablloVittar e Rita Von Hunty. 108 f. Monografia (Especialização em Jornalismo Cultural) - Pontifícia Universidade Católica de São Paulo. Programa de Pós-Graduação em Jornalismo Especializado, São Paulo, 2017.

SANTOS, Joseylson Fagner dos. Femininos de montar - uma etnografia sobre experiências de gênero entre drag queens. 237 f. Dissertação (Mestrado em Antropologia Social) - Universidade Federal do Rio Grande do Norte. Centro de Ciências Humanas, Letras e Artes. Programa de Pós-Graduação em Antropologia, Natal, 2012.

ROCHA, Rose de Melo; POSTINGUEL, Danilo. K.O.: O nocaute remix da drag Pabllo Vittar. In: Anais. XL Congresso Brasileiro De Ciências Da Comunicação Intercom, 40, 2017, Curitiba, PR, 04 a 09/09/2017. Disponível em:

$<\mathrm{http}$ ://portalintercom.org.br/anais/nacional2017/resumos/R12-2955-1.pdf $>$. Acesso em: 22 set. 2017.

SHIRKY, Clay. A cultura da participação: criatividade e generosidade no mundo conectado. Rio de Janeiro: Zahar, 2011.

Lá vem todo mundo: o poder de organizar sem organizações. Rio de Janeiro: Zahar, 2012.

VENCATO, Anna Paula. Fervendo com as drags: corporalidades e performances de drag queens em territórios gueis da Ilha de Santa Catarina. 2002, 132 f. Dissertação (Mestrado em Antropologia Social) - Programa de Pós-Graduação em Antropologia Social, Universidade Federal de Santa Catarina, Florianópolis, 2002.

Recebido em: 30.09 .2017

Aceito em: 18.10.2017

INTERIN, v. 23, n. 1, jan./jun. 2018. ISSN: 1980-5276. 